\title{
Fostering Information Literacy on the Web: Results of a Game-Based Learning Scenario
}

\author{
Vivien Mantei, Joachim Griesbaum, and Thomas Mandl
}

\begin{abstract}
This paper discusses complexities of the Internet as an information space and outlines information behavior patterns of users that are often inadequate. On this basis, game-based approaches to foster information literacy are briefly discussed. This provides the wider frame for an exploratory case study in which the effectiveness and acceptance of game-based elements are investigated. In the case study, a small-scale learning module was created. The goal of the learning module was to sensitize learners with respect to their handling of news and to foster their ability to apply critical thinking skills when evaluating information. The learning module was framed with pre- and post-learning surveys. In these surveys, learners' information literacy skills were compared and their estimation of specific instructional instruments was collected. Two designs of the learning module were compared, a design that included game-based elements and a design without game-based elements Results of the case study are of exploratory value. They indicate, that gamification may be worthwhile because it promotes the transfer of acquired knowledge into real-life behavior. Maybe there is a price to pay. Because of gamification, learners may be more likeable to drop out of the learning scenario.
\end{abstract}

Index Terms-Information literacy, game-based learning, case study.

\section{INTRODUCTION}

Thanks to information technology, we live in a world where information is abundant. Although, on the surface, information research seems easy and simple, it is not. Users are often not capable of successfully wandering through the seas of sometimes incorrect, partly even misleading information that is acquired so easily with search engines [1]. The manifold knowledge bases, and also the dangers of potentially opaque information are not that easily managed. One needs to behave information-literate to be able to find, apply and evaluate available information in a self-determined way and to dwell expediently in this digital space.

The following paper starts with a short introduction into the Internet as a complex and interest-driven, often opaque information space. Following that, typical patterns of human information behavior are shortly sketched. On this basis, conceptual approaches and examples of e-learning systems to foster information literacy are touched on. Then, an exploratory case study is depicted that examines the acceptance and effectiveness of game-based elements in a simple e-learning scenario that tries to foster information

Manuscript received March 23, 2018; revised July 1, 2018.

Vivien Mantei is with the University of Hildesheim, Germany.

Joachim Griesbaum is with the University of Hildesheim, Germany (e-mail: joachim.griesbaum@uni-hildesheim.de).

Thomas Mandl is with the University of Hildesheim, Germany. literacy.

\section{THE INTERNET AS A COMPLEX INFORMATION SPACE}

The Internet is a technical sphere in which innovations may emerge and establish themselves as a mass or niche phenomenon or vanish again. It is a commercial space that fostered and fosters the development of new markets. It provides an ecosystem that has led to new forms of communication and knowledge generation. It establishes a world in which many decisions are made on the basis of automatic, algorithm-based systems. Thus, the Internet can be seen as an indispensable information, communication and transaction infrastructure for users, businesses and even markets and societies. In the following discussion, some characteristics that contribute to the complexity of the Internet as an information space are laid out.

\section{A. Open Infrastructure and Restricted Information Access}

The Internet was (and still is) a unified infrastructure into which further technical inventions may be built. The open infrastructure of the Internet, especially social media, fosters the provision and distribution of information. A prominent example of this kind of information provision and distribution is Wikipedia. But user-generated content is not always considered as valuable. There are many cases in which governments aim to protect or shield their citizens from content that they see as bad. For example, China is expected to oblige users to use their real identities on online platforms, and even to introduce a "social credit system" [2]. In addition, in a move to combat hate speech and fake news, a new law was passed in Germany that specifically targets social networks. This law was widely criticized as restricting free expression and leading to a privatization of censorship [3]. It seems that political regimes are increasingly capable and willing to control information flows.

\section{B. Information and Communication Markets}

The competition on important internet markets has led to a situation in which a small number of enterprises has taken a dominant market position. This is especially true for internet search, an area that is dominated by Google, and for social online networks, dominated by Facebook. Both platforms serve as a kind of media infrastructure that could be part of political regulation, as these companies have got "the power, for example, to command public attention, the power to communicate news and information, or the power to give people a voice" [4]. One also needs to consider their economic power and influence on neighboring markets. Google is suspected of misusing its market leader position in the web search area to promote its other commercial services, 
particularly its shopping search service, thus damaging competition in this field. The European Commission penalized Google with an antitrust fine of 2.42 billion Euros [5]. Both cases show that key markets of the Internet are (in danger of being) dominated by overpowering gatekeepers.

\section{News Media}

Recent years have seen a rise in the dissemination of so-called "post-truth reports" or messages in online news and social media [6]. According to [7], such fake news acquires more interest and is shared more often than debunking articles or real news. [8] trace the establishment of a fake news industry back to two main reasons. First, it is so easy to set up websites. Second, in addition to the possibility of pursuing a specific political agenda, there is the opportunity to employ fake news publishing as a business model and earn money by generating advertising-related income. The topic attracted special attention in the context of the 2016 US presidential election and there was a discussion of the influence of fake news on the outcome of the election. The question of the impact of fake news is rather unclear. [8] point out that fake news "may generate utility for some consumers, but it also imposes private and social costs by making it more difficult for consumers to infer the true state of the world."

\section{Algorithms}

Decisions made by algorithms affect everyone [9]. Extensive user surveillance on the web and the widespread usage of this data undermine the user's sovereignty on data disclosure, as tracking is hidden and private data partly revealed and/or correlated on the basis of information provided by third persons or parties. [9] argue that constant online tracking makes certain groups especially vulnerable, as "online self-disclosure and constant tracking blur traditional concepts of public versus private data, medical versus non-medical data, and human versus automated decision making". They stress the lack of transparency and accountability of automated decision-making, and emphasize that used data may be inaccurate and algorithms may fail.

\section{PATTERNS AND LIMITS OF HUMAN INFORMATION BEHAVIOR}

The last chapter illustrated the complexity of the Internet as an information space. Users have to behave information-literate to successfully pace this complex information space. But how do users actually behave in the search-related contexts?

White [10: 64-82] mentions some central research results. In particular, he reports behavioral biases, such as that people prefer top positions, since they trust the search engines to present the best results first (position bias). Searchers also prefer results that attract their attention by containing images or certain words (e.g., "official", "free") or by means of formatting (e.g., bold). They also favor certain resources (e.g., Wikipedia). [11] reports on statistical data on user interaction with search engines. Accordingly, search sessions are rather short (mean duration of under one minute). Queries typically contain only three keywords. For each query, there is usually no more than one result selected. There are also cognitive biases. [12] investigated and confirmed the existence of confirmation bias - like, for example, the preference for information which supports one's own view, when selecting search results in the context of political information-seeking.

It is, therefore, obvious that users tend to minimize effort, and are prone to errors due to biases in the perception and interpretation of results. Indeed, recent studies provide reason to be concerned. A report from [13] suggests that only a minority of young people can clearly differentiate between commercial and organic results on Google and that some children even think that because something shows up in the Google result pages it must be true. A series of studies, as reported by [1], indicate that the ability to estimate and evaluate information is poorly developed among young users. In sum, we get a rather disillusioned picture concerning users abilities and willingness to thoroughly wander the online information space. The question remains, "How should we change that?"

\section{FOSTERING INFORMATION LITERACY}

The question how to foster users' competency in their information behavior is nothing new. In fact, there are already well thought out frameworks available that provide an orientation and guideline for building up information literacy. For example, in the UK, "A New Curriculum for Information Literacy" (ANCIL) had been worked out in 2011 (https://newcurriculum.wordpress.com/project-reports-and-o utputs/). In ANCIL, information literacy is specified as a continuum of knowledge, competencies, and behavioral patterns. Thus, information literacy concerns users' abilities and motivation to act in an information literate way. A key assumption "is that the way in which information literacy is taught, structured and implemented is as important as the topics" [14]. The American Library Association (ALA), an authority in this field, provides a "Framework for Information Literacy for Higher Education" [15]. According to this, information literacy can be seen as a meta-literacy that encompasses cognitive and ethical components with regard to information usage and online participation. A closer look at two online repositories [16], [17] that collect appropriate learning resources reveals that there is already a multitude of material available online that everyone can use. Some of the learning resources provide audio-visual materials, thus, aiming to realize the increasing potential of multimedia learning for problem-solving [18], some include gamification elements. The effects of the latter are of special interest here.

\section{USING GAMIFICATION TO ENHANCE INFORMATION LITERACY TEACHING SCENARIOS}

Gamification is a trend in e-learning [19]. It is based on the notion that the incorporation of game mechanics in learning settings raises learners' motivation, which leads to better learning outcomes [20]. Research indicates that on the one hand gamification can be worthwhile, but that the positive effects are largely dependent on contextual factors [20]. The knowledge of how to apply game-based elements in specific educational contexts is still limited and empirical use of 
gamification has outpaced knowledge on its mechanisms and methods [21]. Gamification is also applied in learning scenarios that try to improve information literacy, but systematic research is rather scarce here. One exception is the study of [22]. [22] employs a graphical adventure game to teach specific concepts of information literacy, e.g., identifying sources, and reference citing. In their evaluation, participants reached higher information literacy scores than participants in a control condition who learned in a traditional setting (using PowerPoint slides and course materials).

As a starting point for our investigation, we first wanted to get an overview of current practices. Therefore, a benchmark was conducted. Fourteen information literacy-related e-learning sites were analyzed with regard to topic, tasks/learning goals, and game elements. Seven of the sites were selected from [23]; seven were found with the help of the Google search engine. The benchmark indicated that the topics were primarily focused on how to conduct academic work and how to use libraries. Furthermore, most solitary learning scenarios focus on low-level learning according to Bloom's Taxonomy [24] that means the transmission of knowledge, its comprehension and application. Learning scenarios that were connected with courses also exhibited tasks that can be (partially) categorized as high-level learning (analyzing, evaluating, creating knowledge). Table I lists the analyzed scenarios.

TABLE I: BENCHMARK: E-LEARNING SCENARIOS

\begin{tabular}{ll}
\hline \hline Name & Provider \\
\hline Informations- & $\begin{array}{l}\text { Universitätsbibliotheken Augsburg und } \\
\text { Rompetenz }\end{array}$ \\
Lost in Antarctica & $\begin{array}{l}\text { Universitätsbibliothek Braunschweig } \\
\text { (Germany) }\end{array}$ \\
Goblin Threat & Lycoming College (Pennsylvania, USA) \\
Defense of Hidgeon: & University of Michigan (USA) \\
The Plague Years & Universität Düsseldorf (Germany) \\
Aufbruch nach Zyren & University of Michigan (USA) \\
BiblioBouts & Belk Library at Appalachian State \\
The Library Adventure & University, Boon, NC (USA) \\
Game & Utah Valley University Library (USA) \\
LibraryCraft & University of Tennessee at Chattanooga \\
Nightmare on Vine & (USA) \\
Street & James Madison University, Virginia (USA) \\
Citation Tic Tac Toe & James Madison University, Virginia (USA) \\
Magnetic Keyword & Fletcher Library at Arizona State University \\
Quarantined & at the West (USA) \\
I'll Get it! & Carnegie Mellon University Library, \\
Frenetic Filing & Pittsburgh (USA) \\
\hline \hline
\end{tabular}

Table II shows the employed game-based elements.

TABLE II: BENCHMARK: USAGE OF GAME-BASED ELEMENTS

\begin{tabular}{ll}
\hline \hline Game-based element & Frequency of usage \\
\hline Badges & 1 \\
Rankings & 4 \\
Level & 6 \\
Challenges & 2 \\
Game points & 8 \\
Narrative & 10 \\
Feedback & 9 \\
Display of Progress & 7 \\
Avatars & 6
\end{tabular}
Virtual Goods
1
Time limitations
2

Narrative, feedback and game points were the most often used gamification elements.

\section{CASE STUdy}

To explore the acceptance and effectiveness of gamification, an e-learning prototype was evaluated. Unlike the benchmark e-learning scenarios that focus on information literacy in the academic context, the thematic focus of the prototype was on the evaluation of information in the context of fake news in social media. Learners should be sensitized with respect to their handling of news and learn to apply critical thinking skills when evaluating such information. This aspect or problem of information literacy is especially illustrated in the study of [1]. In the following, we will report on the design, execution and results of the case study

\section{A. Design of the Investigation}

The aim of the case study was not to implement a comprehensive collection of relevant content, but to provide a small-scale learning module that could be accomplished in a single learning session. The learning module was framed with pre- and post-learning surveys. In these surveys, probands' information literacy skills were compared and their estimation of specific instructional instruments was collected. Fig. 1 illustrates the test procedure.

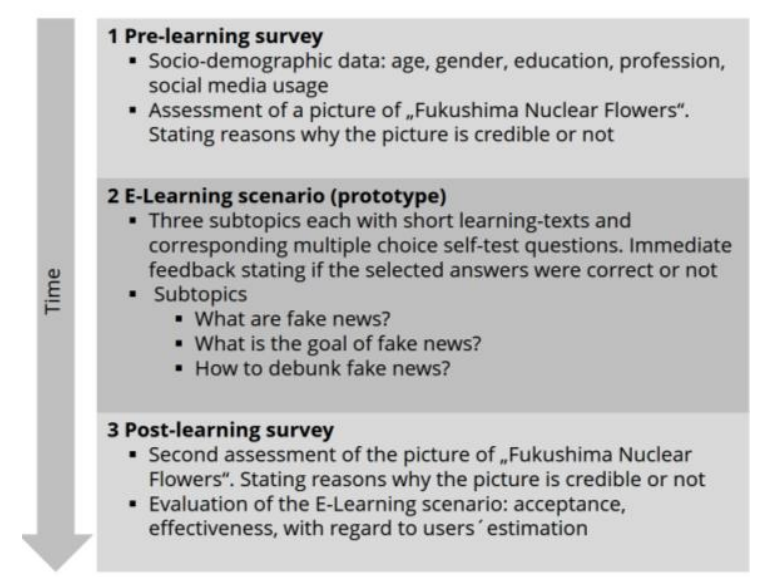

Fig. 1. Test procedure of the case study.

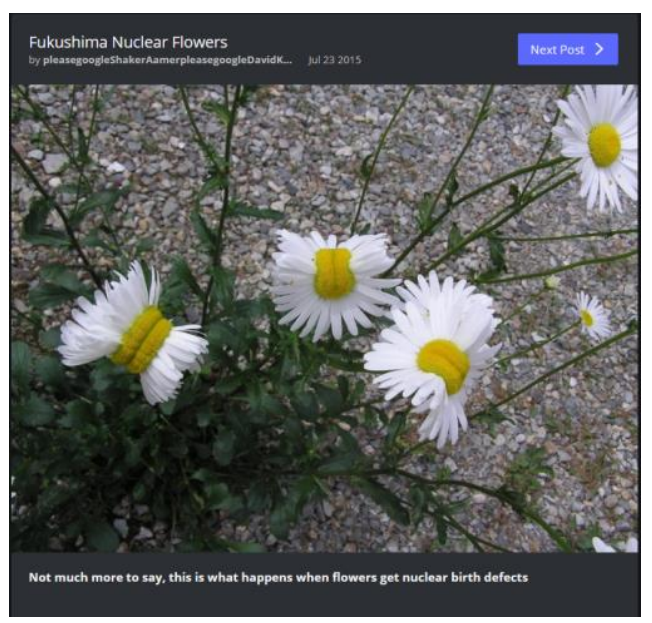

Fig. 2. The so-called "Fukushima Nuclear Flowers". 
The assessment of the so-called "Fukushima Nuclear Flowers" picture was one of the tasks employed in the study of [1] and was adopted for our investigation. The picture is shown in Fig. 2 and can be accessed at https://imgur.com/gallery/BZWWx.

In the test, two designs were compared, a design that included game-based elements (here referred to as GBL, short for Game-Based Learning) and a design without game-based elements (here referred to as Non-GBL).

The following game-based elements were chosen for the GBL design: Narrative, game points, levels/mission, feedback and badges.

Narrative: the narrative was started with a short introductory video. In the video, participants were addressed as secret agent "007". The story tells that the world is in danger and the participant is its last hope for survival as an evil count with the name of "Rumorcula" disseminates fake news to seize power. The participants' tasks as " 007 " are to enlighten the people in order to undermine the credibility of "Rumorcula", thus saving the world. The narrative is included and referred to throughout the e-learning scenario.

Game points and levels/missions: The different subtopics were treated as levels/missions. Participants needed to provide the right answers to the three subtopics, or else they were unable to proceed. If they answered the questions right the first time, participants were granted 100 "trust points". All questions could be answered repeatedly, but "trust points" were only granted if the first try was correct.

Feedback: In addition to the information given if their answer was correct, in GBL when there was a wrong answer, the corresponding learning text was displayed.

Badges: In the GBL design, participants could acquire badges. Badges are granted, immediately after the start of the e-learning scenario for their willingness to fight "Rumorcula", and after the mission was successfully solved.

Table III illustrates the configuration of GBL and Non-GBL conditions in the test design.

TABLE III: TEST DESIGN

\begin{tabular}{|c|c|c|}
\hline $\begin{array}{l}\text { e-learning } \\
\text { Scenario stage }\end{array}$ & GBL-condition & $\begin{array}{l}\text { Non-GBL- } \\
\text { condition }\end{array}$ \\
\hline $\begin{array}{l}\text { 1. Introduction } \\
\text { into the } \\
\text { learning } \\
\text { scenario }\end{array}$ & $\begin{array}{l}\text { Narrative: You (“007”) are the } \\
\text { world's last hope to enlighten the } \\
\text { people from the fake news spread by } \\
\text { the evil count "Rumorcula" }\end{array}$ & $\begin{array}{l}\text { Factual } \\
\text { text } \\
\text { describing } \\
\text { the } \\
\text { learning } \\
\text { scenario }\end{array}$ \\
\hline $\begin{array}{l}\text { 2. Start of the } \\
\text { learning } \\
\text { scenario }\end{array}$ & User is granted a badge "starter" & \\
\hline $\begin{array}{l}\text { 3. Execution of } \\
\text { learning tasks } \\
1-3\end{array}$ & $\begin{array}{l}\text { For each learning task } \\
\text { - User can only proceed if he } \\
\text { provides the correct answers. } \\
\text { - User is granted } 100 \text { "trust points" } \\
\text { if he answered the questions right } \\
\text { the first time } \\
\text { - In case of a wrong answer, the } \\
\text { learning text is redisplayed }\end{array}$ & $\begin{array}{l}\text { User able } \\
\text { to proceed } \\
\text { to the next } \\
\text { learning } \\
\text { task } \\
\text { without } \\
\text { providing } \\
\text { the correct } \\
\text { answers } \\
\text { first }\end{array}$ \\
\hline $\begin{array}{l}\text { 4. End of the } \\
\text { learning } \\
\text { scenario }\end{array}$ & $\begin{array}{l}\text { User is granted a badge "mission } \\
\text { accomplished" }\end{array}$ & \\
\hline
\end{tabular}

As one can see in Table III, the case study employs a between groups quasi-experimental design. The e-learning prototype and the pre- and post-survey were implemented with the help of the SoSci Survey (https://www.soscisurvey.de/). The introductory "Rumorcula" video was generated with the help of the tool Powtoon (https://www.powtoon.com), a software that supports the creation of animated videos.

\section{B. Recruitment of the Sample and Execution of the Study}

The prototype was pre-tested two times and modified in accordance to the feedback provided, e.g., re-wording of survey items. The survey period was started on October 9, 2017 and was stopped on October 17, 2017. Participants were recruited via direct invitations and e-mail-lists within the personal and professional environment of the first author. We had 108 users take part in the study; of these, 57 completed the survey. Four of these were excluded from further analysis as their answers to the open questions indicated that these participants did not take the investigation seriously. Users were randomly assigned to the GBL and Non-GBL condition.

\section{Results of the Case Study}

As a first observation, drop out behavior is different between GBL and Non-GBL. In GBL 59 users started the survey and only $41 \%$ of these $(n=24)$ could be used for further analysis. In Non-GBL the drop out behavior is different as $59 \%(n=29)$ of the users starting the survey could be included into the final analysis. As expected, for both conditions most dropouts happened just after the start. In addition to that, in GBL six participants dropped out during the introduction into the learning scenario when provided with the " 007 " narrative and five participants dropped out during the start of the learning scenario. The reasons here are unclear. It could be that this difference in drop out behavior is just an artefact of the recruiting process. Another, probably more plausible explanation would be that these users did not like the game-based elements and/or tried to minimize efforts and time costs. On the one hand, there is no conclusion here. On the other hand, we need to keep in mind that this behavior possibly relates to users' acceptance of game-based learning.

In the following, we will report results on user acceptance and effectiveness of GBL and Non-GBL.

\section{1) Overview of the test sample}

Table IV provides an overview of the test sample.

TABLE IV: TEST SAMPLE $(N=53)$

\begin{tabular}{|c|c|c|c|c|}
\hline Attribute & Attribute ch & cteristics & & \\
\hline \multirow[t]{2}{*}{ Age } & 20-24 years & $25-34$ years & $>35$ years & \\
\hline & $34 \%$ & $51 \%$ & $15 \%$ & \\
\hline \multirow[t]{2}{*}{ Gender } & female & male & & \\
\hline & $66 \%$ & $34 \%$ & & \\
\hline \multirow[t]{2}{*}{ Education } & $\begin{array}{l}\text { Secondary } \\
\text { school }\end{array}$ & High school & $\begin{array}{l}\text { Appren- } \\
\text { ticeship }\end{array}$ & $\begin{array}{l}\text { Uni- } \\
\text { versity }\end{array}$ \\
\hline & $6 \%$ & $17 \%$ & $28 \%$ & $49 \%$ \\
\hline \multirow[t]{2}{*}{ Profession } & $\begin{array}{l}\text { Pupil/ } \\
\text { Apprentice }\end{array}$ & Student & $\begin{array}{l}\text { Emplo- } \\
\text { yee }\end{array}$ & Other \\
\hline & $6 \%$ & $40 \%$ & $47 \%$ & $8 \%$ \\
\hline \multirow[t]{2}{*}{$\begin{array}{l}\text { Social Media } \\
\text { Usage }\end{array}$} & Any & Facebook & $\begin{array}{l}\text { Insta- } \\
\text { gram }\end{array}$ & $\begin{array}{l}\text { You- } \\
\text { Tube }\end{array}$ \\
\hline & $96 \%$ & $85 \%$ & $49 \%$ & $47 \%$ \\
\hline
\end{tabular}


Table IV shows that the user group that took part in the study was rather young; the average age was 29 years. The majority of probands was female. The level of education was quite high and the large fraction of the participants consists of either students or employees. Nearly everyone uses social media. Apart from Facebook, Instagram and YouTube are popular. According to the Mann-Whitney-U-Test, the sub-samples of the GBL and the Non-GBL conditions do not show significant differences with regard to socio-demographic categories.

\section{2) Learning effectiveness}

Learning effectiveness of the learning module was measured by a comparison of the statements that the users explicated to assess the credibility of the "Fukushima Nuclear Flowers" in the pre-learning survey and the post-learning survey. Each of the answers provided was coded in reliance on the investigation of [1]. [1] categorized statements in three levels. These levels served as an indicator of users' competency grade; the levels were beginning, emerging, and mastery. On the beginning level, students argue that the "Fukushima nuclear flowers" post provides strong evidence or uses incoherent reasoning. At the emerging level, students argue that the post does not provide strong evidence. At the mastery level, students additionally question the source of the post and/or the photograph [1: 17]. All statements were categorized manually by the first author of the paper. According to that, we get the following picture of users' competency as shown in Table V.

TABLE V: USERS ${ }^{\prime}$ COMPETENCY LEVELS BEFORE AND AFTER ACCOMPLISHING THE E-LEARNING MODULE IN PERCENT $(N=53)$

\begin{tabular}{llll}
\hline \hline Survey & Beginning & Emerging & Mastery \\
\hline Pre-learning survey & $47 \%$ & $30 \%$ & $23 \%$ \\
Post-learning survey & $28 \%$ & $32 \%$ & $40 \%$ \\
\hline \hline
\end{tabular}

Twelve (12) participants already showed the highest competency grade at the pre-learning survey. Thus, only 41 could still achieve a higher grade, which means they were able to "learn" as determined in the test design. As one can easily see, the descriptive data indicates that the learning module was effective. Indeed, overall one third (17 out of 53) of participants showed a higher grade of competency in the post-learning survey. Four of them even increased from beginning to mastery. Table VI shows the mean average competence values for both test conditions as measured in the pre-learning survey and the post-learning survey. According to the Wilcoxon signed-rank test, the differences between the grades measured in the pre-learning survey and the post-learning survey are significant $(p=0.001)$; that means learning took place. In a second step, learning in both test conditions (GBL and Non-GBL) is compared. To start, according to the Mann-Whitney-U-Test, the sub-samples of the GBL and the Non-GBL conditions do not differ with regard to their competency levels, neither in the pre-learning survey nor in the post-learning survey. The next step is to investigate if there are differences with regard to learning success. According to the Wilcoxon signed-rank test, there was a competency improvement in both conditions (GBL: $p=0.029$, NGBL: $p=0.008$ ). If we treat the competency categorization data as an interval scale (ranging from 1 for beginning to 3 for mastery), we can compute mean average scores for each condition and illustrate the data values.

TABLE VI: MEAN AVERAGe COMPETENCE VALUES, SCALE RANGING FROM 1 FOR BEGINNING, 2 FOR EMERGING TO 3 FOR MASTERY $(N=53)$

\begin{tabular}{llll}
\hline \hline Condition & $\begin{array}{l}\text { Pre-learning } \\
\text { survey }\end{array}$ & $\begin{array}{l}\text { Post-learning } \\
\text { survey }\end{array}$ & $\begin{array}{l}\text { Competency } \\
\text { growth }\end{array}$ \\
\hline GBL & 1.75 & 2.11 & 0.36 \\
NON-GBL & 1.73 & 2.12 & 0.39 \\
\hline \hline
\end{tabular}

According to the Pearson correlation coefficient, effect size of competency gains can be assessed as strong in both conditions (GBL: $r=0.563$, Non-GBL: $r=0.711$ ). Furthermore, participants assessed the content of the e-learning prototype as well structured and comprehensive (GBL: Mean=4.12, $\mathrm{SD}=1.12$; Non-GBL: Mean=3.96, SD 0.88, Scale: From 1-totally disagree to 5-totally agree). The level of difficulty was estimated as appropriate (Question: "The learning content is too easy for me"; (GBL: Mean=3.00, $\mathrm{SD}=1.10$; Non-GBL: Mean=3.00, SD=0.89, Scale: From 1-totally disagree to 5-totally agree). With regard to these aspects of content evaluation, there were no significant differences in the judgment of participants in GBL and the Non-GBL condition. Due to low data density, we desisted from further analysis. Our interpretation is that significant learning happened in both conditions and that we can not observe differences between the two.

\section{3) Acceptance of prototype and gamification elements}

Acceptance was measured twofold. First, the estimation of all participants with regard to their estimated benefits, learning motivation and satisfaction was measured and compared between both groups. Secondly, GBL-participants were asked for their assessment of the employed game-based elements with regard to their learning motivation.

TABLE VII: COMPARISON WITH REgARd TO SubJeCtive BenEFITS, LEARning Motivation and Satisfaction, Mean Average Competence VAlues (SD), SCALE RANGING FROM 1 FOR TOTALLY DISAGREE TO 5 FOR TOTALLY AGREE, * INDICATES A SIGNIFICANT DIFFERENCE WITH $P<=0.05$ ACCORDING TO THE MANN-WHITNEY-U-TEST, $(N=53)$

\begin{tabular}{|c|c|c|}
\hline Question & $\begin{array}{l}\text { GBL- } \\
\text { condition } \\
\text { Mean } \\
\text { Value (SD) }\end{array}$ & $\begin{array}{l}\text { Non-GBL- } \\
\text { condition } \\
\text { Mean Value } \\
\text { (SD) }\end{array}$ \\
\hline \multicolumn{3}{|l|}{ Benefits } \\
\hline 1. The e-learning scenario is useful & $3.92(0.95)$ & $3.83(1.15)$ \\
\hline $\begin{array}{l}\text { 2. The e-learning scenario helps me to } \\
\text { learn about information literacy in } \\
\text { social media }\end{array}$ & $3.78(1.18)$ & $3.55(1.10)$ \\
\hline $\begin{array}{l}\text { 3. The e-learning scenario encourages } \\
\text { me to scrutinize internet resources } \\
\text { more critically* }\end{array}$ & $4.08(1.04)$ & $3.45(1.00)$ \\
\hline \multicolumn{3}{|l|}{ Motivation } \\
\hline $\begin{array}{l}\text { 1. I have enjoyed using the e-learning } \\
\text { scenario }\end{array}$ & $3.58(1.12)$ & $3.69(1.09)$ \\
\hline 2. The topic is interesting & $3.71(1.10)$ & $3.83(1.09)$ \\
\hline $\begin{array}{l}\text { 3. It is important to learn more on } \\
\text { information literacy in social } \\
\text { media }\end{array}$ & $3.92(1,00)$ & $4.10(0.92)$ \\
\hline \multicolumn{3}{|l|}{ Satisfaction } \\
\hline $\begin{array}{l}\text { 1. I would recommend the e-learning } \\
\text { scenario to others }\end{array}$ & $3.67(1.28)$ & $3.62(1.10)$ \\
\hline $\begin{array}{l}\text { 2. I have enjoyed the presentation of } \\
\text { the topic fake news }\end{array}$ & $3.79(1.08)$ & $3.79(1.16)$ \\
\hline
\end{tabular}


Overall, as Table VII indicates, the e-learning scenario was well perceived. Probands assess it as beneficial. In addition, they were predominantly motivated and satisfied. Although both conditions are, for the most part, estimated comparably, users in the GBL condition have a higher probability of being encouraged to scrutinize internet resources more critically $(\mathrm{p}=0.025)$. With regard to motivation and satisfaction, we see no statistically significant differences. Thus, it seems that game-based components employed in GBL neither led to an increase in motivation nor satisfaction.

But how do the users themselves assess the applied game-based components? Table VIII shows the estimation of motivational effects of the game-based elements applied.

TABLE VIII: ESTIMATION OF THE MOtIVATIONAL EFFECTS OF GAME-BASED ElEMENTS OF THE USERS IN THE GBL-CONDITION, MEAN AVERAge VAlues (SD), SCALE RANGING FROM 1 FOR NOT AT ALL MOTIVATING TO 5 FOR VERY MOTIVATING $(N=24)$

\begin{tabular}{ll}
\hline \hline Game-based element & $\begin{array}{l}\text { GBL-condition } \\
\text { Mean Value (SD) }\end{array}$ \\
\hline Narrative & $3.86(0.88)$ \\
Game points & $4.04(1.27)$ \\
Levels/missions & $3.96(0.93)$ \\
Badges & $3.83(0.99)$ \\
Feedback & $3.73(1.00)$ \\
\hline \hline
\end{tabular}

As one can see, participants assess the game-based elements as fostering motivation. According to the Friedman-Test $(\mathrm{p}=0.404)$, there are no significant differences between the assessments of the different game-based elements; they all seem to be equally motivating.

\section{Estimation of the Case Study}

Overall the e-learning scenario was assessed as worthwhile. The differences observed in participants' argumentation in the pre- and post-learning surveys indicate that the e-learning prototype successfully stimulated learning. With regard to a comparison of GBL and Non-GBL-conditions, results are not that clear-cut. First of all, there are more drop outs in the GBL-condition. Maybe one can assume that the "007" narrative was too childish for some of the participants. With regard to those participants who completed the learning scenario, it is to state that the estimation of benefits, their motivation and satisfaction is predominantly high in both conditions. Here, judgment with regard to future behavior concerning critical evaluation of internet resources is significantly better in the GBL-condition. As this is the most important aim of the e-learning prototype, this aspect deserves further investigation. Bringing both arguments together, one could pose the thesis that game-based elements on the one hand may discourage some users because of their childishness and on the other hand foster the probability of applying the acquired knowledge, because they convey the relevancy of this knowledge in a more convincing way, maybe because of the narrative. This is speculation here, but a possible and worthwhile venue for further investigation. Concerning the motivational effects of the single game-based elements, results indicate that the employed elements were all assessed as fostering motivation. Again, and in contrast to that GBL participants show no higher overall motivation than Non-GBL participants. To conclude, as a whole, the case study was successful in initiating learning. The game-based learning approach did show some peculiarities but seems not to be superior, but also not worse than an approach that does not use such elements.

\section{DISCUSSION}

Overall, this paper touches on many topics and questions. Nevertheless, or, especially for that reason, it is worthwhile and generates news value. First of all, information literacy is laid out as a topic not in a "find and evaluate the right information in a literate way" approach. Rather, it provides a glimpse into the complexities of the Internet as an information space itself. This is an important dimension of information literacy that is often overlooked, even in the modern frameworks. Second, with regard to information behavior, it lays a focus on the evaluation of information and connects with research on information literacy that is not so strongly connected with information seeking in academic contexts but rather concerned with general information behavior. Here, again it is not restricted to technical aspects of information behavior but also trying to build up awareness and motivation on how to be an information literate person.

Beyond these epistemological considerations, the paper also creates new empirical insights in a field in which research is rather scarce. Although only of exploratory value, the case study poses first insights into important questions that enrich current research. If we look at the results, would we assess gamification as worthwhile in a context that aims to foster information literacy? Yes, but according to our data, it is not because learners learn better or because they are more strongly motivated. No. According to our data, gamification could be especially worthwhile because it may promote the transfer of acquired knowledge into real-life behavior. But again, maybe there is a price to pay. Because of gamification, learners may, at the same time, be more likeable to drop out. For now, these are no conclusions but only research questions for further studies. They deserve further investigation.

As an outlook, we would argue that, although our data does not indicate that there is a preference for specific game-based elements, it seems plausible to connect the above argumentation most strongly with the gamification element narrative. Again, this deserves and needs further studies. In posing these assumptions, the authors see the core scientific value of this investigation. They serve as a pathway for further, more specific research. And this corresponds to the request of [20] and [21] to deepen our knowledge on the contextual and mechanical factors of gamification.

\section{REFERENCES}

[1] S. Wineburg, S. McGrew, J. Breakstone, and T. Ortega, "Evaluating information: The cornerstone of civic online reasoning," Stanford Digital Repository, 2016.

[2] I. Williams, "China's internet crackdown is another step toward 'digital totalitarian state'," NBC News, 2017.

[3] C. R. Courtney, "Proposed German legislation threatens broad internet censorship," Committee to Protect Journalists, 2017.

[4] M. Moore, Tech Giants and Civic Power, London: King's College, University of London, Centre for the Study of Media, Communication and Power, 2016.

[5] European Commission, "Antitrust commission fines google $€ 2.42$ billion for abusing dominance as search engine," June 27th, 2017. 
[6] Speed and R. Mannion, "The rise of post-truth populism in pluralist liberal democracies: Challenges for health policy," International Journal of Health Policy and Management, vol. 6, no. 5, pp. 249-51, 2017.

[7] C. Silverman. (2015). Lies, damn lies, and viral content: How news websites spread (and debunk) online rumors, unverified claims and misinformation. Tow Center for Digital Journalism. [Online]. Available:

http://towcenter.org/wp-content/uploads/2015/02/LiesDamnLies_Silv erman_TowCenter.pdf

[8] H. Allcott and M. Gentzkow, "Social media and fake news in the 2016 election," Journal of Economic Perspectives, vol. 31, no. 2, pp. 211-36, 2017.

[9] S. Monteith and T. Glenn, "Automated decision-making and big data: concerns for people with mental illness," Current Psychiatry Reports, vol. 18, no. 12, p. 112, 2016.

[10] R. W. White, Interactions with Search Systems, New York: Cambridge University Press, 2016.

[11] R. Fishkin. (2017). The State of Searcher Behaviour Revealed through 23 Remarkable Statistics. [Online]. Available: https://moz.com/blog/state-of-searcher-behaviour-revealed

[12] S. Knobloch-Westerwick, B. K. Johnson, and A. Westerwick, "Confirmation bias in online searches: Impacts of selective exposure before an election on political attitude strength and shifts," Journal of Computer-Mediated Communication, vol. 20, no. 2, pp. 171-87, 2015.

[13] Ofcom. (2016). Children's Media Lives-Year 3 Findings. [Online]. Available:

https://www.ofcom.org.uk/_data/assets/pdf_file/0015/94002/Childre ns-Media-Lives-Year-3-report.pdf

[14] J. Secker, E. Coonan. (2011). A new curriculum for information literacy: Executive summary. [Online]. Available: http://ccfil.pbworks.com/f/Executive_summary.pdf

[15] American Library Association. (2015). Framework for Information Literacy for Higher Education. Chicago, IL: Association of College \& Research Libraries. [Online]. Available: http://www.ala.org/acrl/standards/ilframework

[16] ACRL, ACRL Framework for Information Literacy Sandbox |A Platform and Repository for Sharing Framework Materials.

[17] Primo. (2017). Peer-reviewed instructional materials online database. [Online]. Available: http://primodb.org

[18] R. E. Mayer, "Multimedia learning: Are we asking the right questions?" Educational Psychologist, vol. 32, no. 1, pp. 1-19, 1997.

[19] S. A. Becker, M. Cummins, A. Davis, A. Freeman, C. G. Hall, and V. Ananthanarayanan, "NMC horizon report: 2017 higher education edition," The New Media Consortium, pp. 1-60, 2017.
[20] J. Hamari, J. Koivisto, and H. Sarsa. "Does gamification work?: A literature review of empirical studies on gamification," System Sciences (HICSS), the 2014 47th Hawaii International Conference, pp. 3025-34, 2014.

[21] C. Dichev and D. Dicheva, "Gamifying education: what is known, what is believed and what remains uncertain: A critical review," International Journal of Educational Technology in Higher Education, vol. 14, no. 1, p. 9, 2017.

[22] M. Kwak, A. Koohang, K. Floyd, and A. Choi, "An educational adventure game for teaching information literacy and student engagement," in Proc. the 51st Hawaii International Conference on System Sciences, January 2018.

[23] L. Eckardt and S. Robra-Baussantz, "Design eines Spiels zum Lernen von Informationskompetenz,“ E-Learning Fachtagung Informatik, pp. 95-106, vol. 14, 2016.

[24] R. Krathwohl, "A revision of bloom's taxonomy: An overview," Theory into Practice, vol. 41, no. 4, pp. 212-218, Autumn 2002.

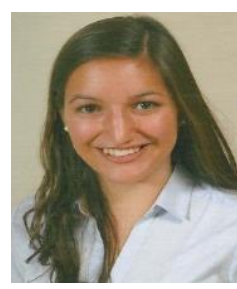

Vivien Mantei graduated from the University of Hildesheim with a master's degree in international information management. Her research focus is e-learning and knowledge management.

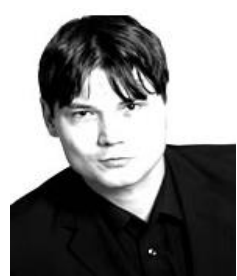

Joachim Griesbaum was born in Lahr/Schwarzwald, Germany, in 1971. He obtained his doctoral degree in information science in 2006 from the University of Konstanz in Germany. In 2008 he joined the University of Hildesheim, Germany, as an assistant professor of information science. His research interests include social media, e-learning, knowledge management, and online marketing.

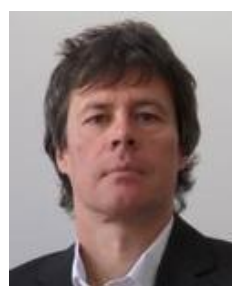

Thomas Mandl obtained his doctoral degree in information science in 2000 from the University of Hildesheim in Germany. His research interests include human-computer interaction, e-learning, and information retrieval. 